Original Article

\title{
PREVALENCE OF METABOLIC SYNDROME IN PATIENTS WITH ARTERIAL HYPERTENSION AND ITS IMPACT ON ASYMPTOMATIC CAROTID ATHEROSCLEROSIS
}

\author{
Svetlana Kostić ${ }^{1}$, Ivan Tasic $^{1,2}$, Dragan Djordjević $^{1,2}$, Viktor Stoičkov $^{1,2}$, Nikola Stojanović $^{1}$ \\ ${ }^{1}$ Institute for Therapy and Rehabilitation "Niška Banja", Niška Banja, Serbia \\ ${ }^{2}$ Faculty of Medicine, University of Niš, Niš, Serbia
}

\begin{abstract}
The importance of metabolic syndrome (MetSy) lies in the fact that its components are proven risk factors for early blood vessel atherosclerosis and thrombosis.Aim of the paper: Our aim was to establish the prevalence of MetSy in patients with arterial hypertension $(\mathrm{AH})$ and its impact on asymptomatic carotid atherosclerosis. The study involved 391 examinees, divided into two groups. The study group consisted of patients with arterial hypertension (n=342; average age, $66.56 \pm 09.52$; with $51 \%$ of female gender). The presence of cardiovascular $(C V)$ risk factors was established for all involved patients, cardiovascular risk score was determined (SCORE risk), laboratory analyses were performed, as well as anthropometric measurements and color Doppler sonography of the great blood vessels of the neck. The patients with AH were divided into two groups according to the presence of MetSy. Metabolic syndrome was confirmed in 198 patients who comprised group I; there were 144 examinees without MetSy and these comprised group II. Those with MetSy had a greater average number of $C V$ risk factors, a higher SCORE risk score, higher body mass index ( $p<0.0001)$, and more frequently had diabetes, hyperlipidemia and obesity. The thickness of the intimal medial complex (IMC) of the carotid arteries was significantly greater in the group with MetSy $(p<0.0001)-51 \%$ of examinees had IMC thickness $\geq 0.90$. The patients with MetSy more commonly had one or more carotid plaques $(p=0.03)$, a higher average number of plaques $(p=0.01)$ and percentage of stenosis $(p=0.01)$. As the most important factors associated with early carotid atherosclerosis, multivariant regression analysis singled out the following (for the model $R=0.512 . R 2=0.262$. adjusted $R 2=0.255$. standard error of the estimate $=0.174 ; p<0.0001$ ): age (coefficiant $\beta=0.331 . p<0.0001$ ), number of MetSy components (coefficient $\beta=0.158$. $p=0.002$ ), level of serum uric acid (coefficient $\beta=0.284 ; p<0.0001$ ). Our results demonstrated a significant association of MetSy and its components with early atherosclerotic changes in the carotid arteries.
\end{abstract}

Key words: metabolic syndrome, arterial hypertension, asymptomatic carotid atherosclerosis, carotid intima-media thickness, carotid plaque.

\section{Introduction}

Metabolic syndrome (MetSy) represents a group of cardiovascular risk factors, such as obesity, hypertension, insulin resistance and dyslipidemia. The importance of MetSy lies in the fact that its components are proven risk factors for early blood vessel atherosclerosis and thrombosis [1], and individuals with MetSy have a three times greater risk to develop cardiovascular complications compared to those who do not have the syndrome $[1,2]$. Further, adult individuals with MetSy are exposed to a five-time greater risk of type 2 diabetes mellitus [3]. There are several definitions of MetSy proposed by various associations, such as World Health Organization (WHO), International Diabetes Federation (IDF), American Heart Association and National Heart, Lung and Blood Institute (AHA/NHLBI), National Cholesterol Education Program, Third Adult Treatment Panel

Correspondence to: Ivan Tasić, M.D., Ph.D.

Faculty of Medicine, 81 Zoran Đinđić Blvd., 18000 Niš, Serbia

Phone: +381648609295

E-mail: dr.ivan.tasic@gmail.com

Received April 24 ${ }^{\text {th }}, 2018$, Accepted December $18^{\text {th }}, 2018$
(NECP/ATP III), and European Group for the Study of Insulin Resistance (EGIR). The definition by the expert team of the Third Panel of the National Cholesterol Education Program is based on the presence of three of the following five criteria: abdominal obesity, hypertriglyceridemia, low HDL cholesterol, elevated blood pressure and hyperglycemia [4]. The prevalence of MetSy varies considerably depending on the criteria used to diagnose the condition.

In patients without manifest cardiovascular disease, the thickness of the intimal medial complex (IMC) and ankle-brachial (pressure) index (ABI) represent noninvasive surrogate markers of atherosclerosis associated with an increased risk for cardiovascular morbidity and mortality [5]. The literature data suggest a clear association between cardiovascular risk factors and intimal medial thickness, as well as between intimal medial thickness and presence of clinical manifestations of coronary disease [6-8]. It has been shown that intimal medial thickness of the carotid arteries directly correlates with the involvement of cerebral, peripheral, and coronary vascular bed by the process of atherosclerosis [6] 


\section{Aim of the paper}

Our aim in this paper was to establish the prevalence of metabolic syndrome in patients with arterial hypertension (AH), as well as its impact on asymptomatic carotid atherosclerosis.

\section{Methods}

The study involved 391 examinees divided into two groups. The study group consisted of the patients with arterial hypertension $(\mathrm{n}=342$; average age, $66.56 \pm$ 09.52 ; with $51 \%$ of women). In all the patients the presence of cardiovascular risk factors was established, cardiovascular risk score was determined (SCORE risk), laboratory analyses were performed, as well as anthropomentric measurements and color Doppler sonography of the great blood vessels of the neck.

\section{Analysis of the risk factors}

Based on the patient history and relevant medical records, the presence of both modifiable and unmodifiable risk factors for cardiovascular diseases was analyzed: $\mathrm{AH}$, hyperlipidemia, smoking, diabetes, obesity, gender and age. Hypertension was defined based on the anamnestic data, medical records, measured systolic blood pressure values of over $140 \mathrm{mmHg}$ and diastolic blood pressure of over $90 \mathrm{mmHg}$, or use of antihypertensive medications. The examinees with total cholesterol values of over $5.0 \mathrm{mmol} / \mathrm{L}$ and/or triglycerides of over $1.7 \mathrm{mmol} / \mathrm{L}$ who were taking hypolipemic therapy were considered to be hyperlipidemic. The presence of diabetes was confirmed based on patient history information, available medical records, measured fasting glucose values of over $5.6 \mathrm{mmol} / \mathrm{L}$, or use of oral hypoglycemic medication or insulin therapy. The examinees with body mass index (BMI) $\geq 30 \mathrm{~kg} / \mathrm{m}^{2}$ were considered to be obese. An interactive electronic version of the SCORE risk charts from the European Society of Cardiology guidelines on CVD prevention (prepared by the Third Joint Working Group of the European Association of Preventive Cardiology - Heartscore) was used to assess the risk of fatal cardiovascular events in our examinees.

Metabolic syndrome was diagnosed in accordance with the NECP/ATP III metabolic syndrome diagnostic criteria (The National Cholesterol Education Program, Adult Treatment Panel).

\section{Laboratory analyses}

General laboratory analyses were done in all the examinees. Values of the following laboratory parameters were measured: total cholesterol, HDL and LDL cholesterol fractions, triglycerides, creatinine, serum uric acid (employing standard laboratory methodology and using a Humastar 600 biochemical analyzer). Creatinine clearance was determined using the Cockcroft-Gault formula.

\section{Anthropometric measurements}

Anthropometric measurements involving body weight, body height, waist and hip circumference measurements were done in all examinees in order to get an insight into their nutritional status. The measurements were performed with light clothes and without any footwear. Body mass index (BMI) was determined using the following formula: body weight in $\mathrm{kg} /$ body height in $\mathrm{m}^{2}$.

\section{Color Doppler sonography (CDS) of the great blood vessels in the neck}

Color Doppler sonography of the great blood vessels in neck was done in all our examinees using the ultrasound scanner system EsaoteBiomedica, My Lab60 Xvision, with a multifrequency linear probe of 4-13 MHz. Intraluminal lesions were determined using B-mode imaging and defined as changes in the form of IMC thickening and appearance of plaques as focal intimal thickenings. IMC thickness was measured in the posterior wall of the common carotid artery $2 \mathrm{~cm}$ away from the top of the bifurcation, in the region without any focal changes. Longitudinal images of the common carotid artery and its branches (internal and external carotid artery) were analyzed bilaterally, determining the diameter of stenosis and analyzing plaque properties. Interpretations were based on the combination of B-mode, i.e. real-time tissue imaging, and Doppler spectral analysis.

\section{Statistical data processing}

The following statistical parameters were presented in the description: arithmetic mean (Xsr), standard deviation (SD), absolute value and percentage (\%) of attributive properties. Comparison of the mean values of numerical properties between the two groups of examinees was done using the Student's t-test. Linear regression analysis (by Spearman) was used to evaluate the association of the factors of interest. The factors demonstrating a considerable impact on dependent variables in univariate analysis were included in multivariate models as independent variables. Statistical data processing was done using the SPSS software, 17.0 version. In all the analyses, the assessment error of 0.05 or $5 \%$ was taken as the cut-off of statistical significance.

\section{Results}

The patients with hypertension were divided into two groups by the presence of MetSy. Metabolic syndrome was confirmed in 198 patients and these comprised group I, while 144 examinees were without MetSy and these comprised group II. There was no age difference between the examinees with and those without MetSy. Those with MetSy had a greater average number of risk factors for cardiovascular diseases (CVD), a higher CV risk score - SCORE, and higher body mass index 
$(\mathrm{p}<0.0001)$, and in this group of patients, diabetes, hyperlipidemia and obesity were more common ( $\mathrm{p}<0.0001)$, (Table 1).

Table 1 Comparison of characteristics of the groups of examinees with and without metabolic syndrome

\begin{tabular}{lrrc}
\hline Characteristic & \multicolumn{1}{c}{$\begin{array}{c}\text { I group } \\
\mathrm{n}=198\end{array}$} & \multicolumn{1}{c}{$\begin{array}{c}\text { II group } \\
\mathrm{n}=144\end{array}$} & $\mathrm{p}$ value \\
\hline Age (in years) & $66.80 \pm 9.76$ & $66.24 \pm 9.17$ & $\mathrm{n} . \mathrm{s}$. \\
Average number of & $2.69 \pm 0.82$ & $1.85 \pm 0.58$ & 0.0001 \\
risk factors & & & \\
SCORE risk & $5.52 \pm 3.13$ & $4.42 \pm 2.68$ & 0.001 \\
Number of MetSy & $3.47 \pm 0.70$ & $1.76 \pm 0.45$ & 0.0001 \\
components & & & \\
Hyperlipidemia (\%) & $162(81.2)$ & $91(63)$ & 0.0001 \\
Diabetes mellitus $(\%)$ & $59(30)$ & $3(2.1)$ & 0.0001 \\
Smoking (\%) & $26(13)$ & $18(12.5)$ & n.s. \\
Obesity (\%) & $110(55.5)$ & $14(9.7)$ & 0.0001 \\
BMI (kg/m $\left.{ }^{2}\right)$ & $30.31 \pm 4.50$ & $25.71 \pm 3.03$ & 0.0001 \\
\hline n.s. - no statistically significant difference between the two groups
\end{tabular}

Examinees from the group I (with MetSy) had higher values of fasting glucose in the serum, higher levels of triglycerides and uric acid $(\mathrm{p}<0.0001)$, and lower values of HDL cholesterol fraction (Table 2).

Table 2 Overview of laboratory analyses performed in the studied groups

\begin{tabular}{lcll}
\hline Characteristic & $\begin{array}{c}\text { I group } \\
\mathrm{n}=198\end{array}$ & $\begin{array}{l}\text { II group } \\
\mathrm{N}=144\end{array}$ & $\mathrm{p}$ value \\
\hline $\begin{array}{l}\text { Glycemia } \\
(\mathrm{mmol} / \mathrm{L})\end{array}$ & $6.25 \pm 1.98$ & $5.47 \pm 1.24$ & 0.0001 \\
$\begin{array}{l}\text { Cholesterol } \\
(\mathrm{mmol} / \mathrm{L})\end{array}$ & $5.52 \pm 1.33$ & $5.71 \pm 1.15$ & 0.14 \\
$\begin{array}{l}\text { LDL-cholesterol } \\
(\mathrm{mmol} / \mathrm{L})\end{array}$ & $3.53 \pm 1.28$ & $3.65 \pm 0.98$ & 0.32 \\
$\begin{array}{l}\text { HDL-cholesterol } \\
(\mathrm{mmol} / \mathrm{L})\end{array}$ & $1.12 \pm 0.27$ & $1.36 \pm 0.35$ & 0.0001 \\
$\begin{array}{l}\text { Triglycerides } \\
\text { (mmol/L) }\end{array}$ & $2.35 \pm 1.51$ & $1.42 \pm 1.05$ & 0.0001 \\
$\begin{array}{l}\text { Uric acid } \\
(\mu \mathrm{mol} / \mathrm{L})\end{array}$ & $348.17 \pm 92.16$ & $302.89 \pm 80.86$ & 0.0001 \\
$\begin{array}{l}\text { Creatinine } \\
(\mu \mathrm{mol} / \mathrm{L})\end{array}$ & $86.86 \pm 22.81$ & $82.11 \pm 22.01$ & 0.05 \\
$\begin{array}{l}\text { Creatinine } \\
\text { clearance }(\mathrm{ml} / \mathrm{min})\end{array}$ & $76.57 \pm 20.55$ & $84.54 \pm 28.37$ & 0.0001 \\
\hline
\end{tabular}

\section{Analysis of color Doppler ultrasound of the great blood vessels in the neck}

The thickness of the carotid IMC was significantly greater in the group with MetSy compared to those without the condition $(\mathrm{p}<0.0001)$, and $51 \%$ of examinees had IMC thickness of $\geq 0.90$. Those with MetSy more commonly had one or more carotid plaques $(\mathrm{p}=0.03)$, a greater average number of plaques $(\mathrm{p}=0.01)$ and a higher percentage of stenosis $(\mathrm{p}=0.01)$ compared to group II examinees (Table 3).
Table 3 Color Doppler sonography of the great blood vessels in the neck in the studied groups

\begin{tabular}{lccc}
\hline Characteristic & $\begin{array}{c}\text { I group } \\
\mathrm{n}=198\end{array}$ & $\begin{array}{c}\text { II group } \\
\mathrm{n}=144\end{array}$ & $\mathrm{p}$ value \\
\hline $\begin{array}{l}\text { Thickness of the carotid } \\
\text { IMC (mm) }\end{array}$ & $0.91 \pm 0.21$ & $0.81 \pm 0.17$ & $<0.0001$ \\
$\begin{array}{l}\text { Increased IMC } \\
\text { thickness, } \mathrm{n}(\%)\end{array}$ & $101(51)$ & $47(32.6)$ & $<0.001$ \\
$\begin{array}{l}\text { Presence of carotid } \\
\text { plaques, } \mathrm{n}(\%)\end{array}$ & $142(71)$ & $88(61)$ & 0.03 \\
$\begin{array}{l}\text { Average number of } \\
\text { plaques }\end{array}$ & $1.62 \pm 1.35$ & $1.27 \pm 1.20$ & 0.01 \\
$\begin{array}{l}\text { Average percentage of } \\
\text { stenosis }\end{array}$ & $41.12 \pm 12.02$ & $37.54 \pm 9.01$ & 0.01 \\
\hline
\end{tabular}

Analyzing the carotid plaque characteristics, it was found that in the MetSy group plaques were most commonly fibrocalcified (29\%), then fibrous (22\%) and calcified (19\%), and in the group without MetSy fibrous plaques were most prevalent (28\%) (Table 4).

Table 4 Carotid plaque characteristics in the studied groups

\begin{tabular}{lcrrr}
\hline $\begin{array}{l}\text { Plaque characteristics, } \\
\mathrm{n}(\%)\end{array}$ & \multicolumn{2}{c}{$\begin{array}{c}\text { I group - } \\
\text { MetSy }\end{array}$} & \multicolumn{2}{c}{$\begin{array}{c}\text { II group - } \\
\text { without MetSy }\end{array}$} \\
\hline Lipid & 0 & $(0)$ & 0 & $(0)$ \\
Fibrolipid & 2 & $(1)$ & 3 & $(2.1)$ \\
Fibrous & 44 & $(22)$ & 40 & $(28)$ \\
Fibrocalcified & 57 & $(29)$ & 31 & $(21.5)$ \\
Calcified & 38 & $(19)$ & 14 & $(9.7)$ \\
\hline
\end{tabular}

As the most significant factors associated with early carotid atherosclerosis, multivariant regression analysis singled out the following (for the model $\mathrm{R}=0.512$. $\mathrm{R}^{2}=0.262$. adjusted $\mathrm{R}^{2}=0.255$. standard error of the estimate $=0.174 ; \mathrm{p}<0.0001$ ): age (coefficiant $\beta=0.331$. $\mathrm{p}<0.0001$ ), number of MetSy components (coefficient $\beta=0.158 . p=0.002$ ), and serum level of uric acid (coefficient $\beta=0.284 ; \mathrm{p}<0.0001)$.

\section{Discussion}

Disorders of lipid and glucose metabolism, obesity and $\mathrm{AH}$ are defined as risk factors for cardiovascular diseases, and these are at the same time the components of MetSy [1]. The prevalence of MetSy has been on the rise worldwide, but it is difficult to establish the prevalence more precisely due to different criteria used to define the condition. The INTERHEART study, performed in 52 countries throughout the world, demonstrated the prevalence of MetSy to be about 26\% [9]. According to the data of the National Health and Examination Survey, the prevalence of MetSy in the United States of America changes with age; in men below 40 years of age it is $20 \%$, and in women of the same age it is $16 \%$, while the prevalence of the condition in individuals of either gender aged over 60 years even exceeds $50 \%$ [10]. 
In our examinees with $\mathrm{AH}$, the prevalence of MetSy was significantly higher compared to controls, as well as the average number of present MetSy components. Those with AH and MetSy had a greater average number of risk factors for cardiovascular diseases, a higher $\mathrm{CV}$ risk score - SCORE, higher BMI, and diabetes, hyperlipidemia and obesity were more common in these individuals (Table 1).

In the PIUMA study in Umbria, Italy, 1.742 examinees without any manifest $\mathrm{CV}$ disease were prospectively observed for 10.5 years on the average; MetSy was established in $34 \%$ of them. Those with MetSy were older, and with longer history of $\mathrm{AH}$ and higher systolic blood pressure values. It was shown that MetSy was an independent predictor of future cardiovascular diseases in individuals of either gender with essential $\mathrm{AH}$, and this prognostic effect of MetSy was not dependent on the traditional cardiovascular factors of risk, including left ventricular hypertrophy and ambulatory blood pressure measurement [11]. In the PIUMA study, the prevalence of diabetes was $14 \%$ [11], while in our examinees with MetSy the prevalence of diabetes was $30 \%$, while in those without MetSy it was $2.1 \%$ (Table 1 ). The study by Marjani et al. showed a rather high prevalence of MetSy in patients with type 2 diabetes, with the percentage being higher in women $(53.27 \%)$ than in men $(48.71 \%)$ [12].

The prevalence of hyperlipidemia in our examinees was rather high $-81.2 \%$ in the first, and $63 \%$ in the second group. Laboratory analyses showed higher values of fasting glucose in the serum in patients with MetSy, higher triglyceride and uric acid levels, and lower values of HDL cholesterol fraction. There were no differences in the values of total and LDL cholesterol, probably due to the fact that the examinees with previously diagnosed hypercholesterolemia were treated with hypolipemic agents and/or employed non-pharmacological treatment measures. In individuals with MetSy, the so called atherogenic dyslipidemia predominates, characterized by increased triglycerides and decreased HDL cholesterol, while LDL may be normal or only slightly elevated. Triglycerides play a significant role in the processes of atherogenesis and thrombogenesis; in a metaanalysis involving 101 prospective studies with 302.430 examinees, it has been confirmed that elevated triglycerides are an important factor associated with the development of coronary heart disease [13].

The studies undertaken in Greece and the USA have shown that the prevalence of metabolic syndrome is similar in both genders [14]. On the other hand, there have been studies indicating a higher prevalence of MetSy in women or in men [15]. In our study, women more commonly had MetSy (59.6\%). Deibert et al. demonstrated a prevalence of MetSy in postmenopausal women of $36.1 \%$ [16]. Furthermore, there have been studies suggesting that the differences in MetSy prevalence may be influenced by genetic factors and ethnicity as well [17].

Cardiovascular risk in individuals with MetSy is the product of different combinations of the components of the syndrome, which are not at all uniform. Each of the components is an independent risk factor for CVD and their synergistic action additionally increases the risk. Cardiovascular mortality is increased with an increasing number of MetSy components [18]. The results of multivariate regression analysis in our study singled out the number of MetSy components as one of the most important factors associated with atherosclerosis of the carotid arteries.

Kuopio Ischaemic Heart Disease Risk Factor Study (KIHD) observed for 11.6 years on the average 1.209 seemingly healthy men aged 42 to 60 years, where it was shown that CVD fatalities were 2.9-4.2 times more common in the presence of MetSy [19]. Among the patients of more advanced age (70-79 years), the presence of MetSy was associated with a higher prevalence of coronary events, myocardial infarction, heart failure and hospitalizations regardless of the cause in the Health, Aging and Body Composition Study (HealthABC study) [20]. In the Medicine, Angioplasty or Surgery Study (MASS II), the patients with stable coronary disease were followed up for two years; those with MetSy had poorer CV outcomes and 2.5 times higher mortality independent of the factors of age, gender, smoking, LDL cholesterol and number of involved coronary blood vessels. The mortality of patients with MetSy was $10.6 \%$ after two years, compared to $5.2 \%$ in those without MetSy [21].

The current European guidelines for CVD prevention in clinical practice, similarly to their predecessors, recommend the use of the SCORE system to assess the risk in asymptomatic patients since it has been based on a large representative European cohort [22]. In all the patients involved in our study SCORE was determined, and the obtained results demonstrated statistically significantly higher SCORE values in those with AH and MetSy (Table 1). The results such as these could be in part expected, since the SCORE system was based on the presence or absence of some of the MetSy components. Non-invasive imaging methods are able to identify asymptomatic atherosclerosis in various arterial areas and therefore supplement the assessment of risk. A special significance of these approaches lies in the detection of changes in their subclinical phase in individuals at high risk for the development of cardiovascular diseases, so that the measures of prevention and appropriate treatments could be timely introduced.

IMC thickness in the common carotid arteries represents a solid indicator of early atherosclerosis [23], and a number of studies, including the Multi-Ethnic Study of Atherosclerosis (MESA) in asymptomatic patients, have shown that the IMC thickness exceeding 75 percentiles for age, gender and race is associated with the risk for myocardial infarction, stroke and cardiovascular mortality independently of other conventional risk factors [24]. The association of MetSy with subclinical atherosclerosis was the subject of a number of studies employing non-invasive imaging techniques. In the study by Holewijn et al., involving 1.517 individuals 
with MetSy aged 50 to 70 years, a significant association was found between asymptomatic atherosclerosis and MetSy, regardless of the employed imaging method [25].

IMC thickness of the carotid arteries in our examinees was significantly greater in the group with MetSy compared to those without MetSy (Table 3), where increased IMC thickness $(\geq 0.90)$ was found in $51 \%$ of examinees with MetSy. Those with MetSy more commonly had one or more carotid plaques, a greater average number of plaques and percentage of stenosis (Table 3). Similar results were published by Olijhoek et al. in the Netherlands, examining the association of MetSy with changes in the coronary, cerebral and peripheral arteries. The prevalence of MetSy in that study was $45 \%$; their patients had greater IMC thickness, a lower anklebrachial index, and more prevalent microalbuminemia compared to those without MetSy. Furthermore, they demonstrated that with an increasing number of MetSy components, IMC thickness increased as well [26].

In our analysis of the characteristics of carotid plaques, we found that in our examinees with MetSy plaques were most commonly fibrocalcified, then fibrous and lastly calcified, while in those without MetSy fibrous plaques predominated (Table 4). However, it was interesting to note that lipid plaques were not present in any of the 342 patients with $\mathrm{AH}$, with or without MetSy. The presence of soft lipid and fibrolipid plaques has been usually associated with the risk for neurological complications (transitory ischemic attacks, reversible ischemic deficits or cerebrovascular insults) due to

\section{References}

1. Isomaa B, Almgren P, Tuomi T, et al. Cardiovascular morbidity and mortality associated with the metabolic syndrome. Diabetes Care 2001; 24:683-689.

2. Eckel RH, Grundy SM, Zimmet PZ. The Metabolic Syndrome Lancet 2005; 365:1415-1428.

3. Stern MP, Williams K, Gonzalez-Villalpando C, Hunt KJ, Haffner SM. Does the metabolic syndrome improve identification of individuals at risk of type 2 diabetes and/or cardiovascular disease? Diabetes Care 2004; 27:2676-2681.

4. Executive Summary of the Third Report of the National Cholesterol Education Program (NCEP) Expert Panel on Detection, Evaluation, and Treatment of High Blood Cholesterol in Adults (Adult. Treatment Panel III). JAMA 2001; 285:2486-2497.

5. Holewijn S, den Heijer M. et al. The Metabolic Syndrome and Its Traits as Risk Factors for Subclinical Atherosclerosis. J Clin Endocrinol Metab 2009; 94 (8):2893-2899.

6. Burke GL, Evans GW, Riley WA, Sharrett AR, Howard G, Barnes RW, Rosamond W, Crow RS, Rautaharju PM, Heiss G, for the ARIC Study Group. Arterial wall thickness is associated with prevalent cardiovascular disease in middle-aged adults. Stroke 1995; 26:386-391.

7. Mannami T, Baba S, Ogata J. Strong and significant relationships between aggregation of major coronary risk factors and the acceleration of carotid atherosclerosis in the general population of a Japanese city. Arch Intern Med 2000; 160:2297-2303

8. Hodis HN, Mack WJ, LaBree L, Selzer RH, Liu CR, Liu CH, Azen SP. The role of carotid arterial intima-media thickness in predicting clinical coronary events. Ann Intern Med 1998; 128:262-269.

9. Jusuf S, Hawken S, Ounpuu S, Bautista L, Franzosi MG, Commerford P, Lang CC,Rumboldt Z, Onen CL, Lisheng L, an increased embolic potential of these plaques [27]. On the other hand, the presence of carotid plaques suggests that plaques in the coronary arteries may be present as well. The presence of less echo-lucent plaques in stable coronary patients has been able to predict acute coronary syndrome in the future, regardless of the presence of other factors of risk [28]. Khoury et al. have demonstrated that patients with multi-vessel coronary disease had a higher carotid plaque score compared to those with single-vessel coronary disease or normal coronary blood vessels [29]. Recent analyses have shown that the presence plaques in the carotid arteries has a greater predictive significance regarding future $\mathrm{CV}$ events, compared to IMC thickness [30].

\section{Conclusion}

Arterial hypertension is commonly associated with metabolic disorders, especially with insulin resistance and MetSy. In our study, we demonstrated that in patients with $\mathrm{AH}$ the prevalence of MetSy was significantly higher than in healthy individuals. Patients with $\mathrm{AH}$ and MetSy had a greater average number of risk factors for cardiovascular diseases, higher score of $\mathrm{CV}$ risk SCORE, higher body mass index, diabetes was more often present, as well as hyperlipidemia and obesity. The results indicated the presence of a significant association between MetSy and its components and atherosclerotic changes in the carotid arteries.

Tanomsup S, Vangai PJr, Razak F, Sharma AM, Anand SS INTERHEART Study Investigationi. Obesity and the risk of myocardial infarction in 27.000 participans from 52 countries: a case-control study. Lancet 2005; 366 (9497):1640-1649.

10. Ervin RB. Prevalence of metabolic syndrome among adults 20 years of age and over, by sex, age, race and ethnicity, and body mass index: United States, 2003-2006. Natl Health Stat Report 2009; 13:1-7.

11. Giuseppe Schillaci, Matteo Pirro, Gaetano Vaudo et al. Prognostic Value of the Metabolic Syndrome in Essential Hypertension. J Am Coll Cardiol 2004; 43:1817-1822.

12. Marjani A, Mojerloo M. The metabolic syndrome in type 2 diabetic subjects in Gorgan, Iran. J Pak Med Assoc. 2011; 61(5):458-461.

13. Triglyceride Coronary Disease Genetics Consortium and Emerging Risk Factors Collaboration, Sarwar N, Sandhu MS, Ricketts SL, Butterworth AS, et al. Triglyceride-mediated pathways and coronary disease: collaborative analysis of 101 studies. Lancet 2010; 375:1634-1639.

14. Athyros VG, Ganotakis ES, Bathianaki M, Monedas I, Goudevenos IA, Papageorgiou AA, Papathanasiou A, et al. Awareness, treatment and control of the metabolic syndrome and its components: a multicentre Greek study. Hellenic J Cardiol 2005; 46(6):380-386.

15. Cameron AJ, Shaw JE, Zimmet PZ. The metabolic syndrome: prevalence in worldwide populations. Endocrinol Metab Clin North Am. 2004; 33(2):351-375.

16. Deibert P, Konig D, Vitolins MZ, Landmann U, Frey I, Zahradnik HP, Berg A. Effect of a weight loss intervention on anthropometric measures and metabolic risk factors in pre versus postmenopausal women. Nutr J 2007; 6:31.

17. Marjani A. A Review on Metabolic Syndrome. J Endocrino Metab 2012; 2(4-5):166-170. 
18. Hu G, Qiao Q, Tuomilehto J et al for the DECODE Study Group. Prevalence of the metabolic syndrome and its relation to all-cause and cardiovascular mortality in nondiabetic European men and women. Arch Intern Med 2004;164:1066-1076.

19. Lakka HM, Laaksonen DE, Lakk TA, et al. The metabolic syndrome and total and cardiovascular disease mortality in middle-aged men. JAMA 2002; 288:2709-2716.

20. Butler J, Rodondi N, Zhu Yet. al. The Health, Aging, and Body omposition Study (Health ABC study). Metabolic Syndrome and the Risk of Cardiovascular Disease in Older Adults. J Am Coll Cardiol 2006; 47:1595-1602.

21. Lopes NH, Paulitsch FS, Pereira AC, et al. Impact of metabolic syndrome on the outcome of patients with stable coronary artery disease: 2-year follow-up of the MASS II study. Coron Artery Dis 2008; 19:383.

22. Piepoli M, Hoes A, Agewall S et al. 2016 European Guidelines on cardiovascular disease prevention in clinical practice The Sixth Joint Task Force of the European Society of Cardiology and Other Societies on Cardiovascular Disease Prevention in Clinical Practice (constituted by representatives of 10 societies and by invited experts). Eur Heart J 2016; 37:2315-2381.

23. Petrović B. Bolesti arterija vrata. Akademska misao. Beograd. 2000; 18-23.

24. Folsom AR, Kronmal RA, Detrano RC, et al. Coronary artery calcification compared with carotid intima-media thickness in the prediction of cardiovascular disease incidence: the MultiEthnic Study of Atherosclerosis (MESA). Arch Intern Med. 2008; 168:1333-1339.
25. Holewijn S, den Heijer M, Swinkels DW, et al. The metabolic syndrome and its traits as risk factors for subclinical atherosclerosis. J Clin Endocrinol Metab 2009;94:2893-2899.

26. Jobien K. Olijhoeka, Yolanda van der Graaf, Jan-Dirk Banga, Ale Algra et al., for the SMART Study Group. The Metabolic Syndrome is associated with advanced vascular damage in patients with coronary heart disease, stroke, peripheral arterial disease or abdominal aortic aneurysm. Eur Heart J 2004; 25:342-348

27. Petrović B. Bolesti arterija vrata. Akademska misao. Beograd. 2000; 56-64.

28. Honda O, Sugiyama S, Kugiyama K, Fukushima H, Nakamura S, Koide S, Kojima S, Hirai N, Kawano $H$, Soejima $H$, Sakamoto T, Yoshimura M, Ogawa H. J Am Coll Cardiol. Echolucent carotid plaques predict future coronary events in patients with coronary artery disease. J Am Coll Cardiol 2004; 43(7):1177-1184.

29. Khoury Z, Schwartz R, Gottlieb S, Chenzbraun A, Stern S and Keren A. Relation of Coronary Artery Disease to Atherosclerotic Disease in the Aorta, Carotid, and Femoral Arteries Evaluated by Ultrasound. Am J Cardiol 1997; 80: 1429-1433.

30. Yoichi Inaba, Jennifer A. Chen, Steven R. Bergmann. Carotid plaque, compared with carotid intima-media thickness, more accurately predicts coronary artery disease events: A metaanalysis. Atherosclerosis 2012; 220:128-133. 